use in this way, but it contains none the less a wealth of information and is the fruit of much care and labour. Provided its purpose is understood it will be found a stimulating addition to the E.C.G. library.

\section{Creative Minds in Medicine}

William Carleton Gibson, D.Phil.(oXon.), M.D.C.M., Professor of the History of Medicine and Science, University of British Columbia, Vancouver, Canada. Pp. xi +238 , illustrated. Springfield, Illinois: Charles C Thomas. I963. \$6.75.

The last half-century has indeed been remarkable for the great advances in scientific medicine and surgery, advances which our distinguished forbears could scarcely have envisaged. The study of the history of medicine has, however, been for the most part neglected until recently. In November of last year the Section of the History of Medicine of the Royal Society of Medicine celebrated its centenary; and the President of the Society, in his introductory address, emphasized the true value and importance of history to the student of medicine. This, as he reminded us, was fully realized by the first President of this Section, Sir William Osler, in 1912. Since then the history of medicine has gradually attracted more attention and now is beginning to take its rightful place in our curriculum.

Dr. Gibson's book is a welcome addition to the literature of the subject. He covers a very wide field, giving personal impressions of many distinguished men from the I8th century onwards. His first chapter furnishes a comprehensive account of Baron Larrey, surgeon to Napoleon's armies (r766-1842), of whom comparatively little has hitherto been written, but who is undoubtedly a striking example of the creative mind. Subsequent chapters include neurology, problems in aviation medicine, the study of physical factors in mental disease, and even contributions by medical men to music and to general literature. Not least among the many interesting pages are those devoted to the contributions by medical undergraduates.

The author has cast his net so widely that one might almost say that his book is too inclusive. He has mentioned so many among our profession, some better known than others, that it has only been possible to give a very brief account of the life and work of each of them individually. For the main purpose of the book this is inevitable, and we do not mean this as a criticism. It has, on the other hand, a definite advantage in that it calls attention to a great number of examples of the creative mind that might otherwise have escaped our notice. There is, however, a good index, and appended to each chapter is a list of selected references. With such documentation this volume should prove a good stimulus to further study of medical history and an encouragement to all those who can perceive the value and importance of the creative mind.

\section{An Introduction to Diagnostic Enzymology}

J. H. Wilkinson, PH.D., D.SC., F.R.I.C. Pp. viii + 288, illustrated. London: Edward Arnold. 1962. $45 s$.

As indicated by its title, this book provides an informative introduction to the rapidly expanding field of clinical enzymology. It should be useful to clinical biochemists as much as to medical students and clinicians.

The opening chapter contains an elementary but easily comprehensible description of the fundamental properties of enzymes, coenzymes, activators and inhibitors, and of the essentials of enzyme kinetics. A short chapter follows which is devoted to the localization of diagnostically important enzymes in the body, the treat气 ment of samples intended for enzyme determination and similar topics of importance to the laborator 8 worker. The next six chapters describe the charace teristics, determination and diagnostic importance of various classes of enzyme, including the digestive enzymes, the phosphatases, transaminases, dehydro $=$ genases, glycolytic enzymes and cholinesterases. Tw chapters deal respectively with enzymes in inborn error홍 of metabolism and with miscellaneous enzymes o $\bar{p}$ diagnostic value and the concluding chapters describథ enzyme tests in myocardial infarction and liver disease and the origin and fate of serum enzymes respectivelyos Useful bibliographies, covering standard works, reviews. and original papers, follow each chapter.

No attempt is made to give detailed descriptions of laboratory methods for enzyme determination, exceptw for eight of the most commonly used methods which appear in an appendix. However, the reader concerne with such details will be able to obtain them withouB. difficulty from the bibliographies, and the outlines of the methods given in the text provide useful guides to the choice of methods.

The text contains some irritating tricks of style, such as the frequent use of the hackneyed word 'cases' wheriv the author means 'patients', and there is some uno necessary verbosity which makes reading difficult ina places. These are minor criticisms, however, which dø not detract from the general usefulness of the book? The volume is clearly printed on good-quality paper with an adequate index.

Pathology of the Upper Respiratory Tract

R. E. REwell, M.D., M.R.C.P. Pp. viii + a illustrated. Edinburgh and London: E. \&cق Livingstone. 1963. 40s.

Monographs on special subjects are tending to replace the standard textbooks of pathology and Dr. Rewell' book is welcome, for ear, nose and throat pathology i\& particularly inadequately covered in the larger works As consultant pathologist to the E.N.T. Infirmary Liverpool, Dr. Rewell has great experience in this fiel\$ and has condensed nearly Io years' work into his book?

The postgraduate student will probably find the book more useful than the morbid anatomist. Etiology an pathogenesis of most conditions are discussed in detaif but histological descriptions are rather inadequate. This is particularly unfortunate, as the photomicrographs frequently do not compensate for inadequacies in the text. The first two chapters deal with the pathology of the nose and sinuses and include a good account of malignant granulomas of the nose. Following this are chapters on the pharynx and larynx. It is surprising that the author makes no mention of the presence of amyloid material in the laryngeal nodule, which is by n\$ means uncommon and immediately afterwards com을 ments on the rarity of amyloid tumours. Major errors and omissions are very few, however, in this part of tho book.

Exception may be taken to the last three chapters devoted to tumours of lymphoid tissue, salivary gland and skin and bones. Together nearly one-third of the book is occupied by these subjects and most of the topics discussed fall outside those usually included oto-rhino laryngology. In an effort to compress such vast field into three chapters the author has inevitabl omitted important material; for example, there is no mention of the relationship of toxoplasmosis to histio cytic medullary reticulosis and much of the discussion of leukæmias is almost incomprehensible.

Little would have been lost by omission of thes 